\title{
Cardiobacterium valvarum infective endocarditis and phenotypic/molecular characterization of 11 Cardiobacterium species strains
}

Correspondence

Jens Jørgen Christensen jejc@regionsjaelland.dk

Received 18 August 2010 Accepted 13 December 2010
Ming Chen, ${ }^{1,2}$ Michael Kemp, ${ }^{1,3}$ Niels E. Bruun, ${ }^{4}$ Jette M. Bangsborg, ${ }^{5}$ Niels Højlyng, ${ }^{6}$ Annemarie Hesselbjerg, ${ }^{1}$ Rimtas Dargis ${ }^{1}$ and Jens Jørgen Christensen ${ }^{1,7}$

${ }^{1}$ Department of Microbiological Surveillance and Research, Statens Serum Institut, Copenhagen, Denmark

${ }^{2}$ Department of Clinical Microbiology, Rigshospitalet, Copenhagen, Denmark

${ }^{3}$ Department of Clinical Microbiology, Odense University Hospital, Odense, Denmark

${ }^{4}$ Department of Cardiology, Gentofte University Hospital, Gentofte, Denmark

${ }^{5}$ Department of Clinical Microbiology, Herlev University Hospital, Herlev, Denmark

${ }^{6}$ Infectious Diseases Unit, Medical Department, Roskilde University Hospital, Roskilde, Denmark

${ }^{7}$ Department of Clinical Microbiology, Slagelse Hospital, Slagelse, Denmark

\begin{abstract}
Cardiobacterium valvarum is a newly recognized human pathogen related to infective endocarditis. Cardiobacterium species are, however, only rarely the aetiology of infective endocarditis. An infective endocarditis case is presented and, additionally, phenotypic and phylogenetic comparison of a further 10 collection strains, representing the two species within the genus, was performed. C. valvarum was isolated from the blood and DNA was present in valvular tissue (partial 16S rRNA gene analysis) from a 64-year-old man with infective endocarditis of the mitral valve, rupture of chordae and prolapse of pulmonary valves in addition to a fluttering excrescence. A mechanical mitral valve and neochordae were inserted successfully.

Phenotypically, the two species within the genus Cardiobacterium resemble each other greatly. When using the Vitek 2 Neisseria-Haemophilus identification card, the reaction for phenylphosphonate was positive for all Cardiobacterium hominis strains, but negative for all $C$. valvarum strains, thereby separating the two species. The two species made up two separate clusters by phylogenetic examination using $16 \mathrm{~S}$ rRNA gene sequence analysis.
\end{abstract}

\section{INTRODUCTION}

The genus Cardiobacterium was created in 1964, including one species, Cardiobacterium hominis, a fastidious, pleomorphic, Gram-negative bacillus (Slotnick \& Dougherty, 1964). The genus Cardiobacterium is one of the members of the HACEK group (Das et al., 1997; Lang \& Morris, 2002; Slotnick \& Dougherty, 1964), a group of Gram-negative bacteria that includes Haemophilus spp., Aggregatibacter actinomycetemcomitans, C. hominis, Eikenella corrodens and Kingella kingae. Before 2004, C. hominis was the only Cardiobacterium species known. Cardiobacterium valvarum was first identified as a novel species by Han et al. (2004) and is a rare aetiological agent of infective endocarditis. Until now, only seven cases of $C$. valvarum infective endocarditis have been reported in the literature (Vaněrková et al., 2010; Geissdörfer et al., 2007; Bothelo et al., 2006; Han, 2005; Han \& Falsen, 2005; Han et al., 2004; Hoffman et al., 2010). In this study, we report a case of infective endocarditis of the mitral valve, rupture of chordae and prolapse of $\mathrm{P} 1$ and $\mathrm{P} 2$ in addition to a fluttering excrescence caused by $C$. valvarum and an analysis of 11 strains of Cardiobacterium species, four of $C$. hominis and seven of C. valvarum.

\section{CASE REPORT}

A 64-year-old man was admitted to the local hospital due to increasing dyspnoea and severe mitral insufficiency. $\mathrm{He}$ worked as a music teacher. He had a 1-year history of moderate mitral valve prolapse and mitral insufficiency diagnosed by echocardiography, and was an outpatient at the cardiology department of the hospital. During the previous year, he had become tired easily and experienced slight dyspnoea when bicycling uphill. 
Eight weeks prior to admission, the patient received a tooth implantation on which occasion he did not receive antibiotic prophylaxis. For the previous several weeks, the patient had experienced febrile episodes, profuse sweating and night shiver episodes. A new episode occurred the night before admission, in addition to low blood pressure and fever of $39.9^{\circ} \mathrm{C}$. On admission, he was afebrile with a blood pressure of $130 / 60 \mathrm{mmHg}$. Auscultation revealed a grade 2 of 6 systolic heart murmur. A light oedema of both ankles was noted. Laboratory examinations showed haemoglobin of $65 \mathrm{~g} \mathrm{l}^{-1}$, leukocyte count of $9.4 \times 10^{9} \mathrm{l}^{-1}$, C-reactive protein of $79 \mathrm{mg} \mathrm{l}^{-1}$, thrombocyte count of $88 \times 10^{9} \mathrm{l}^{-1}$, basic phosphatase of $127 \mathrm{U} \mathrm{l}^{-1}$ (normal range 35-105), bilirubin of $36 \mu \mathrm{mol} \mathrm{l}^{-1}$ (normal range 5-25) and lactate dehydrogenase of $271 \mathrm{U} \mathrm{l}^{-1}$ (normal range 105205). Ultrasound examination of the abdomen was normal. Six blood culture bottles (Bactec Plus aerobic/F bottles) were taken and empirical therapy with intravenous penicillin 5 million units four times daily and gentamicin $120 \mathrm{mg}$ twice daily was initiated.

Four out of the six blood culture bottles taken on initial admission yielded growth of Gram-negative rods after 3 days of incubation. Penicillin was changed to intravenous cefuroxime (1.5 $\mathrm{g}$ three times a day), and the gentamicin treatment was continued. Echocardiography revealed severe mitral insufficiency with mitral valve prolapse, rupture of chordae and prolapse of $\mathrm{P} 1$ and $\mathrm{P} 2$ in addition to a fluttering excrescence. Three days after admission, the patient was moved to the cardiology department at a highly specialized hospital for further treatment.

Ten days after admission, the Gram-negative rods were eventually identified as C. valvarum. Cefuroxime treatment was changed to ceftriaxone $1 \mathrm{~g}$ twice daily.

The patient was operated on 22 days after admission. The mitral valve was replaced with a mechanical valve and neochordae were inserted. While culture was negative, bacterial DNA from C. valvarum was found on the mitral valve by partial $16 \mathrm{~S}$ rRNA gene sequence analysis. The patient received 6 weeks of antibiotic treatment of which 2 weeks was post-operative. The patient was discharged clinically well 78 days after admission without paraclinical signs of infection.

\section{METHODS}

Bacterial culture and strains. The case strain and 10 other strains examined are listed in Table 1. The case strain was isolated from blood samples.

Phenotypic characterization. Strains were cultured on $5 \%$ and $10 \%$ horse-blood agar and chocolate agar plates. Incubation was at $37{ }^{\circ} \mathrm{C}$ in ambient air with and without a supplement of $5 \% \mathrm{CO}_{2}$. Growth at $22{ }^{\circ} \mathrm{C}$ was read for 6 days. Anaerobic growth, on a prereduced medium, was read after incubation for 6 days in an anaerobic jar $\left(70 \% \mathrm{~N}_{2}, 20 \% \mathrm{H}_{2}\right.$ and $\left.10 \% \mathrm{CO}_{2}\right)$. Motility, cellular morphology and Gram-stained smears of all bacterial strains were examined by light microscopy. Phenotypic characterization of strains was mostly conducted using conventional methods as recommended by the Danish Reference Group for Identification of Clinically Important Bacteria (Bruun et al., 1999). $\beta$-Galactosidase production was detected by the method of Kilian \& Bülow (1976) with $0.2 \%$ $o$-nitrophenyl- $\beta$-galactoside. All strains were also tested with an API 20NE kit and the Vitek 2 Neisseria-Haemophilus identification card and read according to the manufacturer's instructions. Antimicrobial susceptibility testing was performed with Neo-Sensitabs (Rosco) on Danish Blood Agar using breakpoints according to the Clinical and Laboratory Standards Institute for Haemophilus species (www.rosco. $\mathrm{dk}$ ) and for tigecycline using Etest. The case strain was also examined by Etest for susceptibility to selected treatment-relevant antibiotics.

Partial 16S rRNA gene sequencing. Partial 16S rRNA gene sequencing of bacterial strains followed by BLAST examination was performed using two amplification primers, BSF8 and BSR1407, producing a $1399 \mathrm{bp}$ fragment; these fragments were sequenced both ways (Christensen et al., 2005). For partial 16S rRNA sequencing of bacterial DNA in valve tissue PCR was done on DNA extracted by a QIAamp DNA Mini kit (Qiagen) using the primers BSF8 and BSR534, which produce a 526 bp product (Christensen et al., 2005). All fragments were sequenced both ways. The edited sequences were compared to deposited sequences in the NCBI 'bacteria' database (BLAST examination) and evaluated for the best and second best taxon matches taking into consideration the percentage identity (number of identical bases between the query and the subject sequence in the database), Max scores (indication of alignment concordance) and Evalues (indication of statistical significance of a given alignment). Partial 16S rRNA sequencing of bacterial DNA in valve tissue was done as previously described (Koch et al., 2010).

\section{RESULTS}

\section{Phenotypic characterization}

Growth characteristics. The phenotypic features of the 11 strains were compared. When incubated in ambient air supplemented with $5 \% \mathrm{CO}_{2}$ on $5 \%$ and $10 \%$ horse blood agar as well as on chocolate agar, all strains grew with colonies $<1 \mathrm{~mm}$ after $24 \mathrm{~h}$ incubation and with grey colonies sized 1-2 $\mathrm{mm}$ after $48 \mathrm{~h}$ incubation, except for four strains [CCUG 12990, CCUG 31208, CCUG $48245^{\mathrm{T}}$ (C. valvarum) and CCUG 31207 (C. hominis)], which had not grown after $24 \mathrm{~h}$, but grew with small colonies sized $<1 \mathrm{~mm}$ after $48 \mathrm{~h}$. Colonies were similar, being small, round, opaque, smooth, grey and glistening. For all strains there was slight $\alpha$-haemolysis on blood agar plates. There was no difference in colony morphology between $C$. valvarum and $C$. hominis, and no difference in morphology on $5 \%$ and $10 \%$ blood agar and chocolate agar plates. Strains were Gram-negative rods that varied in size, typically being pleomorphic and some had pointed ends. All strains were facultatively anaerobic and non-motile. Some strains had an acidulous smell.

Biochemical reactions. All strains were oxidase-positive, catalase-negative and nitrite reductase-negative, except for one C. hominis strain (CCUG 31207) which was nitrite reductase-positive. All strains produced acid from glucose (no gas), maltose, mannitol, mannose, sorbitol and sucrose, but not from lactose or galactose. Eight out of eleven strains were indole-positive. Ten out of eleven 
Table 1. Characteristics of the 11 Cardiobacterium strains examined and the results of near full-length (1399 bp) $16 \mathrm{~S}$ rRNA gene sequence analysis

\begin{tabular}{|c|c|c|c|c|c|c|c|c|}
\hline \multirow[t]{2}{*}{ Strain designation $(s)^{*}$} & \multirow[t]{2}{*}{$\begin{array}{l}\text { Source and } \\
\text { disease/year }\end{array}$} & \multirow{2}{*}{$\begin{array}{c}\text { Species } \\
\text { designation of } \\
\text { strain/best } \\
\text { taxon match }\end{array}$} & \multirow[t]{2}{*}{$\begin{array}{l}\text { Max } \\
\text { score }\end{array}$} & \multirow{2}{*}{$\begin{array}{c}\text { Identities } \\
\text { of base } \\
\text { composition }\end{array}$} & \multirow{2}{*}{$\begin{array}{l}\text { No. of } \\
\text { identical } \\
\text { taxon } \\
\text { match }\end{array}$} & \multicolumn{2}{|c|}{$\begin{array}{l}\text { Difference to second } \\
\text { best taxon match }\end{array}$} & \multirow[t]{2}{*}{$\begin{array}{c}\text { Second } \\
\text { best match }\end{array}$} \\
\hline & & & & & & $\begin{array}{l}\text { Max } \\
\text { score }\end{array}$ & $\begin{array}{c}\text { Base } \\
\text { composition }\end{array}$ & \\
\hline $\begin{array}{l}\text { Case strain (SSI: } \\
\text { AB2924) }\end{array}$ & Blood, endocarditis/2006 & C. valvarum & 2470 & $\begin{array}{c}1345 / 1350 \\
(99 \%)\end{array}$ & 5 & 240 & $\begin{array}{c}1314 / 1365 \\
(96 \%)\end{array}$ & C. hominis \\
\hline (SSI: AB2089) & Blood, endocarditis/1983 & C. hominis & 2435 & $\begin{array}{c}1367 / 1381 \\
(98 \%)\end{array}$ & 1 & 200 & $\begin{array}{c}1312 / 1364 \\
(96 \%)\end{array}$ & C. valvarum \\
\hline $\begin{array}{l}\text { CCUG }(\mathrm{EF}) 2711^{\mathrm{T}} \\
\text { ATCC } 15826, \text { NCTC } \\
10426 \text { (SSI: AB2098) }\end{array}$ & Blood, endocarditis/1965 & C. hominis & 2441 & $\begin{array}{c}1367 / 1376 \\
(99 \%)\end{array}$ & 1 & 200 & $\begin{array}{c}1312 / 1359 \\
(96 \%)\end{array}$ & C. valvarum \\
\hline $\begin{array}{l}\text { NCTC } 10666 \\
\text { (SSI: AB 1616) }\end{array}$ & Blood, endocarditis/1966 & C. hominis & 2448 & $\begin{array}{c}1367 / 1381 \\
(98 \%)\end{array}$ & 1 & 298 & $\begin{array}{c}1312 / 1364 \\
(96 \%)\end{array}$ & C. valvarum \\
\hline $\begin{array}{l}\text { CCUG } 31207 \text { (SSI: } \\
\text { AB2167, Kilian C22) }\end{array}$ & Human tooth plaque/1985 & C. hominis & 2423 & $\begin{array}{c}1320 / 1320 \\
(100 \%)\end{array}$ & 2 & 236 & $\begin{array}{c}1280 / 1326 \\
(96 \%)\end{array}$ & C. valvarum \\
\hline $\begin{array}{l}\text { CCUG (EF) } 13150 \\
\text { (SSI: AB2102) }\end{array}$ & $\begin{array}{l}\text { Human subgingival pocket } \\
\text { periodontitis/1982 }\end{array}$ & C. valvarum & 2432 & $\begin{array}{c}1366 / 1380 \\
(98 \%)\end{array}$ & 5 & 226 & $\begin{array}{c}1322 / 1381 \\
(95 \%)\end{array}$ & C. hominis \\
\hline CCUG 12990 & $\begin{array}{l}\text { Human subgingival } \\
\text { pocket, amelogenesis } \\
\text { imperfecta/1982 }\end{array}$ & C. valvarum & 2752 & $\begin{array}{c}1490 / 1490 \\
(100 \%)\end{array}$ & 5 & 406 & $\begin{array}{c}1381 / 1435 \\
(96 \%)\end{array}$ & C. hominis \\
\hline CCUG (EF) 13094 & $\begin{array}{l}\text { Human subgingival } \\
\text { pocket/1982 }\end{array}$ & C. valvarum & 2481 & $\begin{array}{c}1345 / 1346 \\
(99 \%)\end{array}$ & 5 & 212 & $\begin{array}{c}1328 / 1378 \\
(96 \%)\end{array}$ & C. hominis \\
\hline $\begin{array}{l}\text { CCUG } 31208 \text { (SSI: } \\
\text { AB2168, Kilian C50) }\end{array}$ & $\begin{array}{c}\text { Human tooth } \\
\text { plaque/1985 }\end{array}$ & C. valvarum & 2756 & $\begin{array}{c}1492 / 1492 \\
(100 \%)\end{array}$ & 5 & 394 & $\begin{array}{c}1383 / 1434 \\
(96 \%)\end{array}$ & C. hominis \\
\hline $\begin{array}{l}\text { CCUG } 48245^{\mathrm{T}}, \mathrm{MDA} \\
\text { 3079, DSM 17211, } \\
\text { ATCC BAA-694, } \\
\text { NCTC 13294, CIP } \\
108480\end{array}$ & $\begin{array}{l}\text { Blood, endocarditis, } \\
\text { ruptured cerebral } \\
\text { aneurysm/2001 }\end{array}$ & C. valvarum & 2758 & $\begin{array}{c}1493 / 1493 \\
(100 \%)\end{array}$ & 5 & 412 & $\begin{array}{c}1383 / 1437 \\
(96 \%)\end{array}$ & C. hominis \\
\hline CCUG 53031 & $\begin{array}{l}\text { Blood, aortic valve } \\
\text { replacement } / 2006\end{array}$ & C. valvarum & 2217 & $\begin{array}{c}1200 / 1200 \\
(100 \%)\end{array}$ & 5 & 245 & $\begin{array}{c}1161 / 1208 \\
(96 \%)\end{array}$ & C. hominis \\
\hline
\end{tabular}

*ATCC, American Type Culture Collection, Manassas, VA, USA; CCUG, Culture Collection of the University of Göteborg, Sweden; NCTC, National Collection of Type Cultures, Colindale, England; SSI, Statens Serum Institute, Copenhagen, Denmark (SSI strain with internal SSI number).

strains were sucrose-positive. All strains were tested with an API 20NE kit, but there were no positive reactions. Table 2 shows the positive and variable biochemical reactions of the 11 strains in the Vitek 2 Neisseria-Haemophilus identification card wells. Eleven wells containing the following substances were read as negative for all strains: arginine arylamidase, glycogen, $\beta$-galactopyranoside indoxyl, maltotriose, L-proline arylamidase, ornithine decarboxylase, Llysine-arylamidase, D-galactose, phosphorylcholine, urease, D-malate and D-xylose. Three reactions were positive for all strains and seven reactions were variable among both species (see Table 2). One reaction, the well containing phenylphosphonate, was positive for all C. hominis strains, but negative for all $C$. valvarum strains, thereby being useful in separating the two species. Results obtained by automatic reading were as follows: two strains were identified as Kingella kingae (CCUG 53031 and AB2924, acceptable identifications), one strain (CCUG 48245) could not be identified, and all other strains were identified as $C$. hominis (acceptable-excellent identifications).

Antimicrobial susceptibility. All 11 strains were sensitive to penicillin, ampicillin, mecillinam, cefuroxime, ceftazidime, piperacillin/tazobactam, moxifloxacin, gentamicin, ciprofloxacin, colistin and tigecycline (by Etest with MIC range $\left.0.125-1 \mu \mathrm{g} \mathrm{ml}^{-1}\right)$. All strains were sensitive to erythromycin, except for two strains [CCUG 53031 (C. valvarum) and SSI: AB2089 (C. hominis)] which were resistant and intermediate-susceptible, respectively. The case strain was also shown by Etest to be susceptible to penicillin (MIC $0.094 \mu \mathrm{g} \mathrm{ml}^{-1}$ ), ampicillin (MIC $0.025 \mu \mathrm{g}$ $\mathrm{ml}^{-1}$ ), moxifloxacin (MIC $0.032 \mu \mathrm{g} \mathrm{ml}^{-1}$ ), ciprofloxacin 
Table 2. Positive and variable test results obtained when using the Vitek 2 Neisseria-Haemophilus identification card on 11 Cardiobacterium strains

Substrates with negative test results for all strains are given in Methods.

\begin{tabular}{|c|c|c|}
\hline \multirow[t]{2}{*}{ Substrate in well } & \multicolumn{2}{|c|}{$\begin{array}{c}\text { Tests positive or } \\
\text { variable among strains }\end{array}$} \\
\hline & $\begin{array}{l}\text { C. valvarum } \\
(n=7)\end{array}$ & $\begin{array}{l}\text { C. hominis } \\
(n=4)\end{array}$ \\
\hline \multicolumn{3}{|c|}{ Test result different for the two species } \\
\hline Phenylphosphonate & $0 / 7$ & $4 / 4$ \\
\hline \multicolumn{3}{|c|}{$\begin{array}{l}\text { Positive or predominantly positive } \\
\text { test results for both species }\end{array}$} \\
\hline Leucine arylamidase & $7 / 7$ & $4 / 4$ \\
\hline Ellman & $7 / 7$ & $4 / 4$ \\
\hline D-Glucose & $7 / 7$ & $4 / 4$ \\
\hline Phenylalanine arylamidase & $6 / 7$ & $4 / 4$ \\
\hline Maltose & $7 / 7$ & $4 / 4$ \\
\hline Saccharose/sucrose & $6 / 7$ & $4 / 4$ \\
\hline \multicolumn{3}{|c|}{$\begin{array}{l}\text { Negative or predominantly negative } \\
\text { test results for both species }\end{array}$} \\
\hline L-Glutamine & $0 / 7$ & $1 / 4$ \\
\hline$\alpha$-Arabinosidase & $1 / 7$ & $0 / 4$ \\
\hline Pyruvate & $2 / 7$ & $0 / 4$ \\
\hline D-Ribose 2 & $0 / 7$ & $2 / 4$ \\
\hline \multicolumn{3}{|l|}{$\begin{array}{l}\text { Variable test results within and } \\
\text { among the two species }\end{array}$} \\
\hline$\gamma$-Glutamyltransferase & $4 / 7$ & $4 / 4$ \\
\hline D-Mannose & $4 / 7$ & $4 / 4$ \\
\hline L-Pyrrolidonyl arylamidase & $6 / 7$ & $1 / 4$ \\
\hline Phosphatase & $6 / 7$ & $0 / 4$ \\
\hline Tyrosine arylamidase & $1 / 7$ & $1 / 4$ \\
\hline Ala-Phe-Pro-arylamidase & $3 / 7$ & $3 / 4$ \\
\hline$N$-Acetyl-D-glucosamine & $2 / 7$ & $3 / 4$ \\
\hline
\end{tabular}

(MIC $0.004 \mu \mathrm{g} \mathrm{ml}^{-1}$ ) and meropenem (MIC $0.004 \mu \mathrm{g}$ $\left.\mathrm{ml}^{-1}\right)$.

\section{$16 S$ rRNA gene sequencing and phylogenetic analysis}

Table 1 shows the results obtained by 16S rRNA gene sequencing and subsequent BLAST examination of the bacterial strains. Seven and four strains were identified as $C$. valvarum and $C$. hominis, respectively. The phylogenetic trees (Fig. 1a, b) show that strains within the two species were very similar and that the two species were well separated. $C$. valvarum strains had sequence similarities ranging between 98 and $100 \%$, Max scores between 2217 and 2758, and Max score differences to the next best taxon match, which for all strains was C. hominis, ranging from 212 to 412 . C. hominis strains had sequence similarities ranging between 98 and $100 \%$, Max scores between 2423 and 2435, and Max score differences to the next best taxon match, which for all strains was C. valvarum, ranging from 200 to 298 .
Partial 16S rRNA gene sequence examination of the surgically removed valve showed C. valvarum as best match with a Max score of 857 and number of identities being 469 out of 471 , with $C$. hominis as second best match (score 719 bits, 449 of 476 identities).

\section{DISCUSSION}

Infective endocarditis is most commonly caused by Staphylococcus aureus, coagulase-negative staphylococci and streptococci (McDonald, 2009). Up to $3 \%$ of cases of infective endocarditis are attributable to HACEK organisms (Das et al., 1997). Bacteria in this group have in common a culture requirement for an enhanced $\mathrm{CO}_{2}$ atmosphere and the ability to infect human heart valves. C. valvarum is also a new member of the HACEK group and was first reported by Han et al. (2004). The first reported strain was grown from the blood of a 37-year-old man who had insidious endocarditis with a sudden rupture of a cerebral aneurysm. Characterization of the organism through phylogenetic and phenotypic analyses revealed a novel species of Cardiobacterium, Cardiobacterium valvarum.

At least seven previous cases of infective endocarditis caused by $C$. valvarum have been reported worldwide (Vaněrková et al., 2010; Geissdörfer et al., 2007; Bothelo et al., 2006; Han \& Falsen 2005; Han et al., 2004; Hoffman et al., 2010). In six reported cases, blood cultures yielded growth of C. valvarum strains and in one case bacteriological diagnosis was made by $16 \mathrm{~S}$ rRNA gene amplification, sequencing and BLAST examination of valvular tissue alone; in two cases, bacteriological diagnosis was obtained by a positive blood culture as well as by molecular examination of valvular tissue, as in the case described here. In five of the previously described cases, the aortic valves were involved (in one case in addition to the tricuspid valves), and in one case, details were not given. Of the five cases of aortic involvement, one was fatal (infection in a prosthetic valve) and valve replacement was performed in three cases. The ruptured intracranial aneurysm described by Han et al. (2004) illustrates the propensity of $C$. valvarum to cause an embolism, a feature it has in common with $C$. hominis as well as its tendency to cause exceptionally low grade and insidious infections (Das et al., 1997).

The present case adds to the description of the infective potential of C. valvarum as it was the mitral valve that was harmed and rupture of chordae occurred. Valve replacement was needed and neochordae were inserted. The patient described in the present report had a 1-year history of a moderate mitral valve prolapse and mitral insufficiency diagnosed by echocardiography and had received a tooth implantation 8 weeks prior to admittance. Most reported $C$. valvarum infective endocarditis cases were related with periodontal diseases. Four of the strains were isolated from the oral cavity of patients with periodontitis, subgingival pockets or tooth plaque, further supporting 

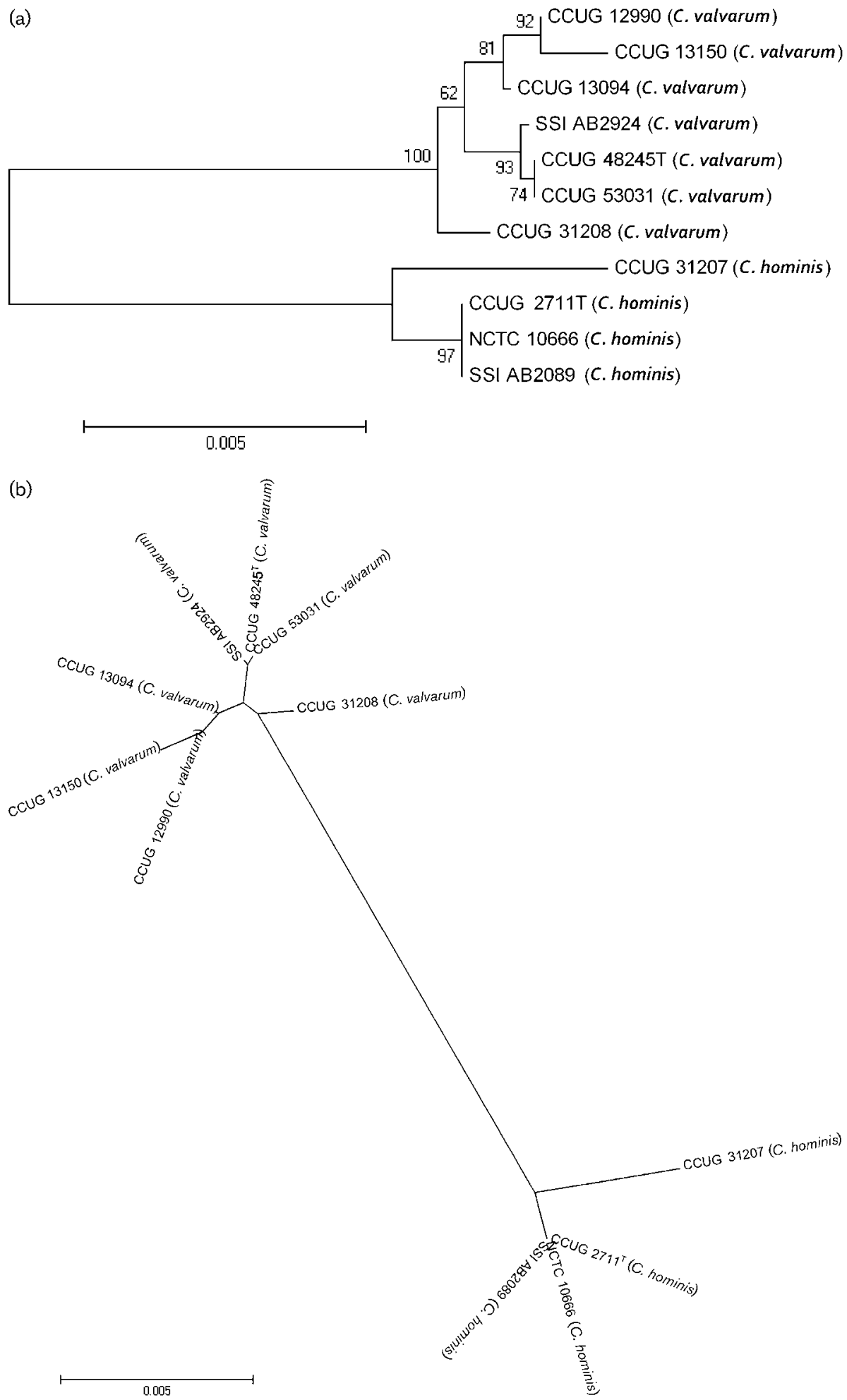

Fig. 1. (a) Phylogenetic tree determined on the basis of the sequences of the 16S rRNA gene obtained by the unrooted neighbour-joining method in the MEGA (version 4.0) program package. The scale bar indicates the evolutionary distance between the sequences determined by calculation of the per cent sequence divergence. It clearly divides the two species $C$. hominis and C. valvarum into two groups. (b) Minimal evolution algorithm (suppressed) obtained by using the MEGA (version 4.0) program and based on the $16 \mathrm{~S}$ rRNA gene. It clearly divides the two species C. hominis and C. valvarum into two groups. 
that the most probable way of the bacterium entering the bloodstream is via the upper respiratory tract.

C. valvarum has been described as a fastidious Gramnegative bacillus that grows better on sheep blood agar than on chocolate agar. In contrast to $C$. hominis, $C$. valvarum should grow more slowly, be non-haemolytic on sheep blood agar, and not utilize sucrose, maltose or mannitol (Han et al., 2004). However, phenotypic tests may not always allow the two Cardiobacterium species to be distinguished and different phenotypic methodologies may give different results as seen with regard to results obtained for acid production from sucrose, maltose and mannitol. In such cases, genotypic identification is a good help and should be performed. Phenotypic characterization analysis shows that $C$. valvarum and $C$. hominis have many reactions in common. When using conventional methods, the only difference we found between these two Cardiobacterium species was acid production from raffinose, which for C. hominis strains was positive. However, no acid was produced from raffinose by $C$. hominis in the report by Han \& Falsen (2005). It is difficult to distinguish $C$. valvarum and $C$. hominis from their phenotypic characterization. No reactions were positive among reactions included in the API 20NE kit. Automatic reading when using the Vitek 2 Neisseria-Haemophilus Identification Card did not separate the two species as the database only includes C. hominis. However, results from the well containing phenylphosphonate seem useful as a test separating the two species. One research group (Geissdörfer et al., 2007) used the API NH identification system, which is commonly used for identification of Haemophilus species and Neisseria species of clinical importance. The outcome of the reactions was well defined, but resulted in a misidentification as Haemophilus parainfluenzae. Therefore, they concluded that API NH may be used for determination of key reactions in the case of fastidious Gramnegative rods such as C. valvarum, but for final identification, molecular tools, e.g. 16S rRNA gene sequence analysis, are indispensable. The present data show that C. valvarum and C. hominis are susceptible to many antibiotics. These data are consistent with previous data also showing sensitivity to most used $\beta$-lactams. The patient described here was treated successfully with cefuroxime and ceftriaxone.

Conventional methods for microbial identification require the recognition of differences in morphology, growth, enzymic activity and metabolism to define genera and species. As seen above, C. hominis and C. valvarum have many similarities and few different reactions. Full-length and partial 16S rRNA gene sequencing methods have emerged as useful tools for identifying phenotypically aberrant and relatively non-aberrant micro-organisms and have made major contributions to taxonomy within the last decades. When performing short (526 bp) and near full-length (1399 bp) 16S rRNA gene sequence analysis all examined strains convincingly were allocated to either $C$. hominis or C. valvarum. These results are in accordance with the results reported in the individual case reports. Phylogenetic trees based on $16 \mathrm{~S}$ rRNA gene sequence analysis clearly divided the examined strains into the two species. One group (Petti et al., 2005) examined three blood-culture strains received for further identification, of which one turned out to be C. valvarum, where the initial phenotypic identifications were erroneous. The authors conclude that this may have misled clinicians, and potentially impacted patient care; $16 \mathrm{~S}$ rRNA gene sequencing is a more objective identification tool, unaffected by phenotypic variation or technologist bias, and has the potential to reduce laboratory errors. In two of the case reports, the presence of C. valvarum $16 \mathrm{~S}$ rRNA gene sequences was also demonstrated in removed valvular tissue, as in our case.

In conclusion, we describe what is believed to be the eighth case of infective endocarditis due to C. valvarum, and the first case affecting the mitral valves and with ruptured chordae. Clinical microbiologists and physicians should be aware that C. valvarum is a potential agent of infective endocarditis when HACEK strains are isolated from blood cultures. Our data show that C. valvarum and C. hominis strains have high phenotypic resemblance with few differentiating reactions, which makes us speculate that some of the early $C$. hominis strains identified by phenotypic methods might be C. valvarum. 16S rRNA gene sequence analysis has proved to be a very useful and reliable tool for identifying strains and confirming their presence in valvular tissue.

\section{REFERENCES}

Bothelo, E., Gouriet, F., Fournier, P. E., Roux, V., Habib, G., Thuny, F., Metras, D., Raoult, D. \& Casalta, J. P. (2006). Endocarditis caused by Cardiobacterium valvarum. J Clin Microbiol 44, 657-658.

Bruun, B., Christensen, J. J., Frederiksen, W., Heltberg, O., Justesen, T. \& Poulsen, L. (1999). Referenceprogram for identifikation af klinsk vigtige bakterier, herunder nomenklatur. http:// www.dskm.dk/pdf/rapporter/DSKM-rapporter/referenceprogram_for_ identifikat.htm

Christensen, J. J., Andresen, K., Justesen, T. \& Kemp, M. (2005). Ribosomal DNA sequencing: experiences from use in the Danish Reference Laboratory for Identification of Bacteria. APMIS 113, 621628.

Das, M., Badley, A. D., Cockerill, F. R., Steckelberg, J. M. \& Wilson, W. R. (1997). Infective endocarditis caused by HACEK microorganisms. Annu Rev Med 48, 25-33.

Geissdörfer, W., Tandler, R., Schlundt, C., Weyand, M., Daniel, W. G. \& Schoerner, C. (2007). Fatal bioprosthetic aortic valve endocarditis due to Cardiobacterium valvarum. J Clin Microbiol 45, 2324-2326.

Han, X. (2005). Cardiobacterium valvarum endocarditis. Ann Intern Med 143, 614.

Han, X. Y. \& Falsen, E. (2005). Characterization of oral strains of Cardiobacterium valvarum and emended description of the organism. J Clin Microbiol 43, 2370-2374.

Han, X. Y., Meltzer, M. C., Woods, J. T. \& Fainstein, V. (2004). Endocarditis with ruptured cerebral aneurysm caused by Cardiobacterium valvarum sp. nov. J Clin Microbiol 42, 1590-1595. 
Hoffman, M. J., Macrie, B. D., Taiwo, B. O. \& Qi, C. (2010). Prosthetic valve/conduit infection caused by Cardiobacterium valvarum. Infection 38, 245-246.

Kilian, M. \& Bülow, P. (1976). Rapid diagnosis of Enterobacteriaceae. I. Detection of bacterial glycosidases. Acta Pathol Microbiol Scand [B] 84B, 245-251.

Koch, A., Svendsen, C. B., Christensen, J. J., Bundgaard, H., Vindfeld, L., Christiansen, C. B., Kemp, M. \& Villumsen, S. (2010). Q fever in Greenland. Emerg Infect Dis 16, 511-513.

Lang, S. D. R. \& Morris, A. J. (2002). Cardiobacterium hominis. In Antimicrobial Therapy and Vaccines, pp. 173-178. Edited by V. L. Yu, R. Weber \& D. Raoult. www.antimicrobe.org
McDonald, J. R. (2009). Acute infective endocarditis. Infect Dis Clin North Am 23, 643-664.

Petti, C. A., Polage, C. R. \& Schreckenberger, P. (2005). The role of $16 \mathrm{~S}$ rRNA gene sequencing in identification of microorganisms misidentified by conventional methods. J Clin Microbiol 43, 6123-6125.

Slotnick, I. J. \& Dougherty, M. (1964). Further characterization of an unclassified group of bacteria causing endocarditis in man: Cardiobacterium hominis gen. et sp. n. Antonie van Leeuwenhoek 30, 261-272.

Vaněrková, M., Žaloudíková, B., Němcová, E., Juránková, J., Pol, J., Černý, J., Němec, P. \& Freiberger, T. (2010). Detection of Cardiobacterium valvarum in a patient with aortic valve infective endocarditis by broad-range PCR. J Med Microbiol 59, 231-234. 